\title{
QUALIDADE SANITÁRIA DE SEMENTES DE MILHO EM DIFERENTES ESTÁDIOS DE MATURAÇÃO'
}

\author{
FERNADO AUGUSTO HENNING ${ }^{2}$, ELIAS ABRAHÃO JACOB JUNIOR², \\ LILIANE MARCIA MERTZ ${ }^{3}$, SILMAR TEICHERT PESKE ${ }^{4}$
}

\begin{abstract}
RESUMO - O presente estudo foi conduzido com o objetivo de avaliar a qualidade sanitária de sementes de linhagens de milho, colhidas em diferentes estádios de maturação. Foram utilizadas três linhagens de milho, as quais são empregadas como parentais fêmeas na produção de híbridos simples comerciais. Para determinação da época de colheita das sementes foi realizada a marcação das plantas no campo, iniciando-se na floração, quando $50 \%$ das plantas apresentavam os estigmas exteriorizados. A partir dos 40 dias após a floração, iniciou-se a colheita dos materiais, em intervalos de quatro dias até o ponto de maturidade fisiológica, o qual foi determinado através da observação da linha de transformação em amido, "linha de leite”. A análise sanitária das sementes foi avaliada através do método do papel filtro. Para verificar o efeito da incidência de fungos sobre a qualidade fisiológica das sementes, realizaram-se os testes de germinação e vigor (envelhecimento acelerado e teste de frio). As sementes de milho apresentaram elevada incidência dos fungos Aspergillus flavus, Penicillium sp. e Fusarium moniliforme, sendo que, a incidência destes microorganismos diminui à medida que as sementes atingem o ponto de maturidade fisiológica. Além disso, a incidência desses microorganismos não afeta a qualidade fisiológica das sementes colhidas no ponto de maturidade fisiológica.
\end{abstract}

Termos para indexação: ponto de colheita, qualidade fisiológica, Zea mays, linha de leite.

\section{HEALTH OF MAIZE SEEDS AT DIFFERENT MATURATION STAGES}

\begin{abstract}
The objective of the present study was to evaluate the health of maize seeds at different maturation stages. Three inbred maize lines, which served as the female parent to produce commercial hybrids, were used. Plants, which had shown $50 \%$ of their stigmas at flowering, were marked to determine the harvest time. Seed harvest began 40 days after flowering and occurred at 4-day intervals up to physiological maturity, which was determined by milk line formation. Seed health was evaluated by the blotter test. To determine the effect of seed health on physiological seed quality, germination and vigor tests (accelerated ageing and cold tests) were done. The results showed that maize seeds had a high incidence of fungi Aspergillus flavus, Penicillium sp. and Fusarium moniliforme, but microorganism incidence decreased as the physiological maturity point was reached. The fungi did not affect physiological seed quality.
\end{abstract}

Index terms: harvest point, physiological quality, Zea mays, milk line.

${ }^{1}$ Submetido em 25/08/2009. Aceito para publicação em 03/03/2010.

${ }^{2}$ Doutorandos do Programa de Pós-Graduação em Ciência e Tecnologia de Sementes, UFPel, FAEM. Caixa Postal 354, CEP: 96010-900, Pelotas - RS, fernandohenning@yahoo.com.br.
${ }^{4}$ Professora Adjunto do Departamento de Fitotecnia, UFSM, CCR. lilianemertz@yahoo.com.br

4Professor titular do Departamento de Fitotecnia, UFPel, FAEM, peske@ ufpel.edu.br. 


\section{INTRODUÇÃO}

Durante o processo de maturação das sementes, a ocorrência de condições ambientais adversas, o ataque de insetos e microorganismos favorecem o processo de deterioração. Assim, o retardamento da colheita pode ocasionar perdas à qualidade fisiológica e sanitária das sementes, devendo ser realizada no momento adequado, o mais próximo possível do ponto de maturidade fisiológica, para reduzir ao máximo as possíveis perdas.

Geralmente, os parâmetros utilizados para indicar a época de colheita de sementes de milho são os teores de água, o máximo acúmulo de matéria seca e o aparecimento da camada negra. Entretanto, esses parâmetros podem sofrer alterações devido a fatores climáticos, genéticos e de manejo, não constituindo um indicativo seguro do ponto de colheita (Afuakwa e Crookston, 1984; Borba et al., 1994; Feesel et al., 2001).

Alguns autores têm sugerido que a "linha de leite", camada transitória entre a matriz sólida e líquida do endosperma em maturação, pode ser utilizada como método para monitorar a maturidade fisiológica e o ponto de colheita das sementes de milho (Afuakwa e Crookston, 1984; Hunter et al., 1991; Tekrony e Hunter, 1995; Faria et al., 2002).

Nesse sentido, estudos detalhados sobre o assunto são extremamente importantes para poder fornecer informações básicas para determinação da época mais indicada para a colheita de espécies de importância econômica, como é o caso do milho. Outro ponto a ser considerado é que no milho, devido à elevada depressão por endogamia, as linhagens apresentam baixa produtividade, o que dificulta o processo de obtenção de sementes e encarece o custo da produção de híbridos simples. Sendo assim, torna-se imprescindível a adoção de medidas que venham a preservar a qualidade fisiológica dessas sementes.

Um dos aspectos que devem ser observados no momento da colheita das sementes é a sua sanidade, em que a presença de fungos associados às sementes de milho pode ocasionar prejuízos a sua qualidade fisiológica Cicero e Silva (2003). Segundo Shurtleff (1986) e Lucca-Filho (1987) os fungos Fusarium moniliforme, Helminthosporium maydis, Colletotrichum graminicola, Aspergillus spp. e Penicillium sp. são associados ao apodrecimento de sementes de milho e a morte de plântulas em pré ou pós-emergência.

Trabalhos já foram conduzidos relacionando linha de leite com qualidade fisiológica das sementes, entretanto, informações que relacionem linha de leite e qualidade sanitária de sementes ainda são escassas. Diante do exposto, o objetivo do trabalho foi avaliar a qualidade sanitária de sementes de linhagens de milho, colhidas em diferentes estádios de maturação.

\section{MATERIAL E MÉTODOS}

O experimento foi instalado no estado de Minas Gerais, na Cidade de Uberlândia, sendo todos os campos cultivados sob irrigação por pivô central, utilizando parcelas com 100 metros de comprimento e cinco metros de largura.

Foram utilizados três genótipos de milho, sendo estes, linhagens fêmeas as quais são utilizadas na produção de sementes híbridas. Para determinação da época de colheita das sementes, realizou-se a marcação das plantas, iniciando-se na floração, quando $50 \%$ das plantas apresentavam os estigmas exteriorizados, procurandose assim, selecionar plantas que apresentavam o mesmo estádio de desenvolvimento.

A partir dos 40 dias após a floração iniciou-se a colheita dos materiais em intervalos de quatro dias até o momento em que as sementes atingiram o ponto de maturidade fisiológica, o qual foi determinado pela "linha de leite". Considerou-se que as sementes atingiram o ponto de maturidade fisiológica quando estas apresentavam a linha de leite no estádio 4 da escala de Hunter et al. (1991), com $75 \%$ do endosperma solidificado. A avaliação foi através da inspeção visual de todas as sementes presentes na espiga, utilizando-se três espigas de cada uma das quatro repetições.

Para determinação da umidade das sementes por ocasião da colheita, utilizou-se o método de destilação em equipamento marca Gehaka e modelo - CA 25 II.

Para os testes de laboratório, foram colhidas 50 espigas de cada repetição as quais foram secadas à temperatura constante de $35{ }^{\circ} \mathrm{C}$ até atingirem $12 \%$ de umidade. Após a secagem, as sementes foram debulhadas e armazenadas em câmara com temperatura média de $10^{\circ} \mathrm{C}$ e umidade relativa de $50 \%$ até seu envio para o laboratório para as análises.

Qualidade Sanitária: Avaliada através do teste do papel filtro (Neergaard, 1979). Foram utilizadas três repetições de 200 sementes para cada época de colheita. As sementes foram colocadas sobre três folhas de papel filtro, previamente umedecidas, em caixas plásticas tipo gerbox, sendo utilizadas 20 sementes por caixa. Em seguida as amostras foram incubadas a temperatura de $20 \pm 2{ }^{\circ} \mathrm{C}$, por um período de sete dias em regime 
luminoso de 12 horas de luz. Finalizado esse período, as sementes foram examinadas individualmente com auxílio de microscópio estereoscópio com aumento de até 60x. Quando necessário, foram preparadas lâminas microscópicas para a identificação dos fungos.

Teste de germinação: Foram utilizadas três repetições de 200 sementes (quatro sub-amostras de 50 sementes) as quais foram colocadas sobre papel germitest umedecido com água destilada na razão de 2,5: 1 (peso de água $\mathrm{x}$ peso do papel). Em seguida, as amostras foram levadas ao germinador, regulado à temperatura constante de $25^{\circ} \mathrm{C}$. A avaliação foi realizada aos oito dias após a semeadura e os resultados foram expressos em porcentagem de plântulas normais (Brasil, 1992).

Envelhecimento acelerado: As sementes de cada amostra foram distribuídas em camada uniforme, sobre a superfície de uma tela de aço inoxidável adaptada em caixa plástica gerbox adicionando-se ao fundo de cada caixa $40 \mathrm{~mL}$ de água destilada. Em seguida, as amostras foram incubadas em câmara do tipo B.O.D. regulada a $42{ }^{\circ} \mathrm{C}$, onde permaneceram por 120 horas. Passado este período, as sementes foram colocadas para germinar sobre papel germitest seguindo os mesmos procedimentos do teste de germinação. Foram utilizadas três repetições de 200 sementes (quatro subamostras de 50 sementes). A avaliação foi realizada no sétimo dia após a semeadura e os resultados foram expressos em porcentagem de plântulas normais.

Teste de frio: Foram utilizadas três repetições de 200 sementes (quatro subamostras de 50 sementes) as quais foram colocadas sobre papel germitest umedecido com água destilada na razão de 2,5: 1 (peso de água x peso do papel). Em seguida, as amostras acondicionadas em sacos plásticos e incubadas à temperatura de $10^{\circ} \mathrm{C}$, durante sete dias e após transferidas para o germinador, seguindo a metodologia utilizada para o teste de germinação.

O delineamento estatístico foi o inteiramente casualizado com quatro repetições. Os dados obtidos foram submetidos à análise de variância e regressão polinomial pelo programa Winstat (Machado e Conceição, 2003).

\section{RESULTADOS E DISCUSSÃO}

Quando se observam os dados de qualidade fisiológica das sementes de milho (Tabela 1), é possível constatar que a linha de leite é um indicador eficiente do ponto de colheita, pois quando as sementes apresentaram a linha de leite no estádio quatro ( $75 \%$ do endosperma solidificado), obteve-se elevada qualidade fisiológica, com germinação igual ou superior a $99 \%$ e vigor, determinado pelo envelhecimento acelerado e pelo teste de frio, igual ou acima de $90 \%$, nas três linhagens avaliadas. Esses resultados concordam com dados obtidos por outros pesquisadores, como trabalho conduzido por Tekrony e Hunter (1995), os quais encontraram máximo nível de vigor no estádio quatro de linha de leite. Ainda de acordo com trabalho conduzido por Faria et al. (2002), observouse que as maiores porcentagens de germinação e vigor foram observadas em sementes colhidas a partir do estádio três de linha de leite.

TABELA 1. Qualidade fisiológica e teor de água de sementes de linhagens de milho, colhidas no ponto de maturidade fisiológica, determinado pela linha de leite no estádio 4, safra 2007/08.

\begin{tabular}{ccccc}
\hline Linhagens de milho & Germinação (\%) & Envelhecimento acelerado (\%) & Teste de Frio (\%) & Teor de água (\%) \\
\hline 1 & 99 & 90 & 99 & 34 \\
2 & 99 & 95 & 98 & 36 \\
3 & 100 & 98 & 99 & 33 \\
\hline
\end{tabular}

Com relação aos teores de água das sementes (Tabela 1), os valores variaram em torno de $35 \%$ o que concorda com trabalho conduzido por Fahl et al. (1994), os quais verificaram que as sementes de milho entre os estádios três e quatro de linha de leite, o qual correspondia ao ponto de maturidade fisiológica, apresentavam teor de água de 35\%. Entretanto, segundo Afuakwa e Crookston (1984), a determinação da umidade possui limitações para ser utilizada como indicador do ponto de colheita, por sofrer influências genéticas e ambientais. Faria et al. (2002), verificaram teores de água variando entre 35 e $42 \%$, em sementes de milho de diferentes genótipos 
colhidas no estádio 4 de linha de leite.

$\mathrm{Na}$ análise sanitária para as três linhagens avaliadas foram encontrados os mesmos gêneros de fungos, Aspergillus flavus Link, Penicillium sp. e Fusarium moniliforme Sheldon (Gráficos 1 a 3). Segundo Cicero e Silva (2003), os prejuízos à qualidade fisiológica de sementes de milho, acarretados por Aspergillus spp. e Fusarium moniliforme foram maiores que de Penicillium sp. Dentre os fungos frequentemente encontrados em sementes de milho, os mais importantes são Fusarium moniliforme, Diplodia maydis, Penicillium sp. e Aspergillus spp., uma vez que podem contribuir para a redução do poder germinativo das sementes LuccaFilho (1984).

No que se refere à quantidade total de fungos associados às sementes de milho, observou-se comportamento semelhante para as três linhagens avaliadas, com maior incidência destes microorganismos em sementes provenientes das primeiras épocas de colheita, decrescendo à medida que a estas atingem o ponto de maturidade fisiológica (Figuras 1 a 3 ).

$\mathrm{Na}$ linhagem 1 (Figura 1), observou-se que o fungo Penicillium sp., apesar de apresentar uma alta incidência, não foi significativo na análise de regressão. Para os fungos Aspergillus flavus e Fusarium moniliforme, foram encontradas relações lineares significativas, apresentando a mesma tendência observada para a quantidade total de fungos com uma diminuição da incidência na medida em que aproximouse o ponto de maturidade. Tanaka e Correa (1981) observaram influência na germinação e na emergência de plântulas em sementes de feijão infectadas com os fungos Aspergillus spp. e Penicillium sp. Entretanto, de acordo com os resultados dos testes de germinação e vigor obtidos nesse trabalho (Tabela 1), mesmo com uma alta incidência de fungos, as sementes colhidas no ponto de maturidade fisiológica apresentaram excelente desempenho demonstrando que não ocorreram prejuízos à qualidade em decorrência da ação dos fungos. Vale ressaltar ainda, que neste trabalho, a secagem das sementes foi realizada imediatamente após a colheita, evitando dessa forma os processos deteriorativos ocasionados pela ação desses fungos. Outro fator que deve ser considerado, é que o armazenamento de sementes em condições adequadas pode contribuir significativamente para a redução na quantidade de fungos. Em trabalho conduzido por Martins-Filho et al. (2001), observou-se que após o armazenamento das sementes de soja, ocorreu redução da incidência dos fungos, o que pode ser atribuído principalmente à perda da viabilidade do inóculo presente como contaminante superficial na forma de esporos.

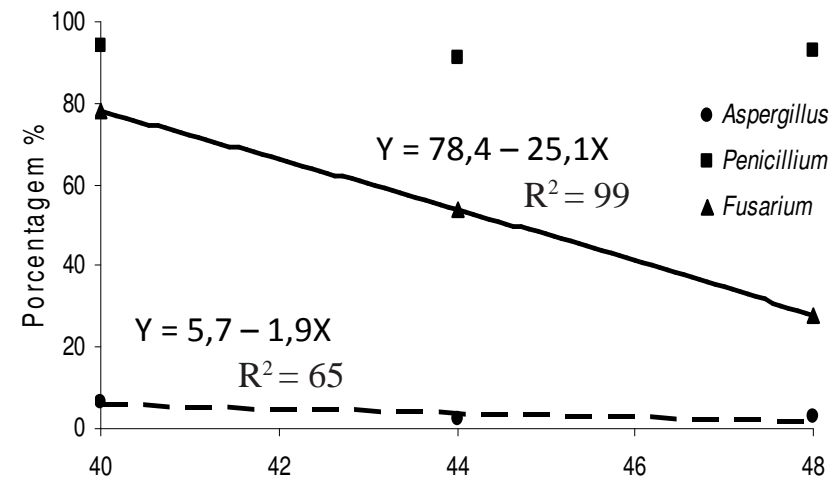

A

Dias após a antese

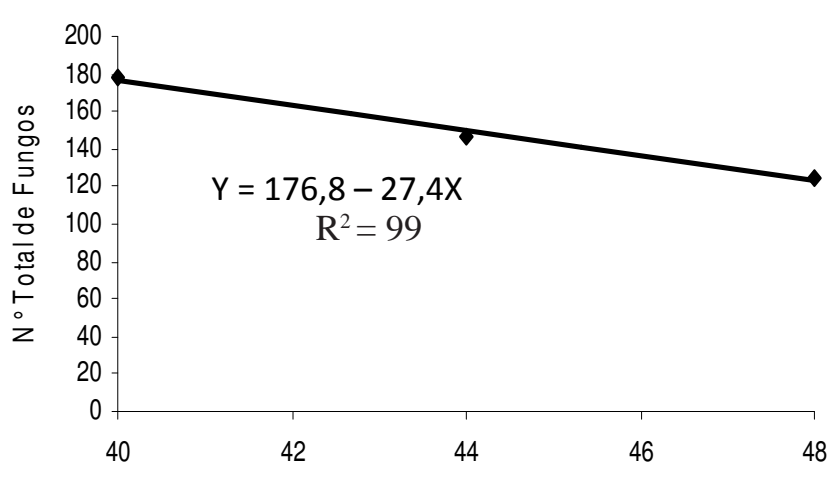

B

Dias após a antese

FIGURA 1. Análise de regressão para os resultados do testes de sanidade de sementes de milho da linhagem 1. A Incidência dos fungos Aspergillus flavus, Penicillium sp. e Fusarium moniliforme; B - Número total de fungos em amostras de 100 sementes 

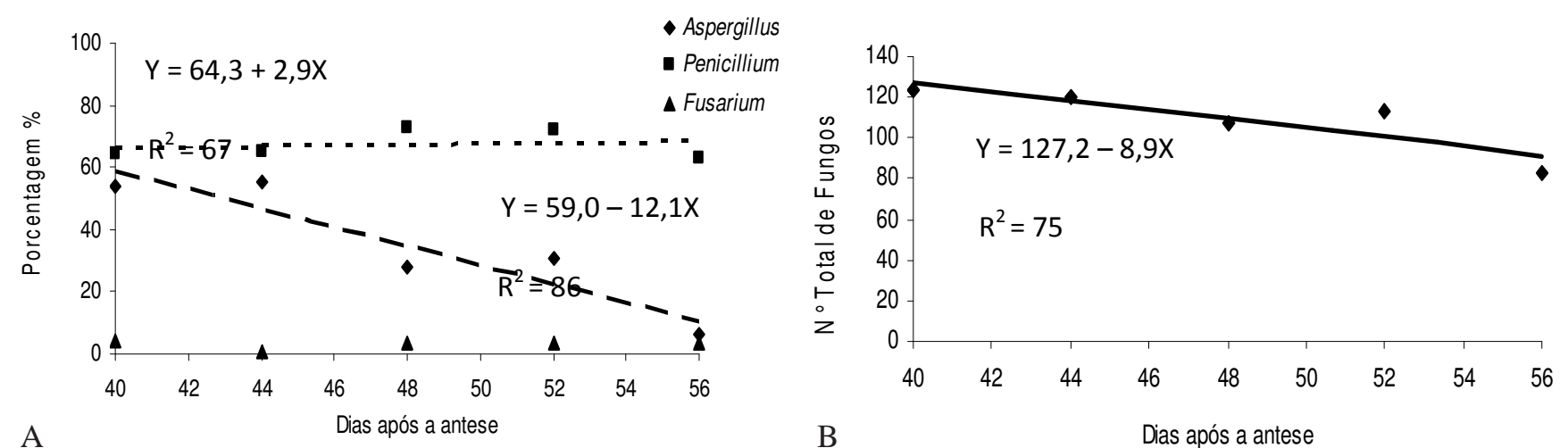

FIGURA 2. Análise de regressão para os resultados do testes de sanidade de sementes de milho da linhagem 2. A -Incidência dos fungos Aspergillus flavus, Penicillium sp. e Fusarium moniliforme; B - Número total de fungos em amostras de 100 sementes.
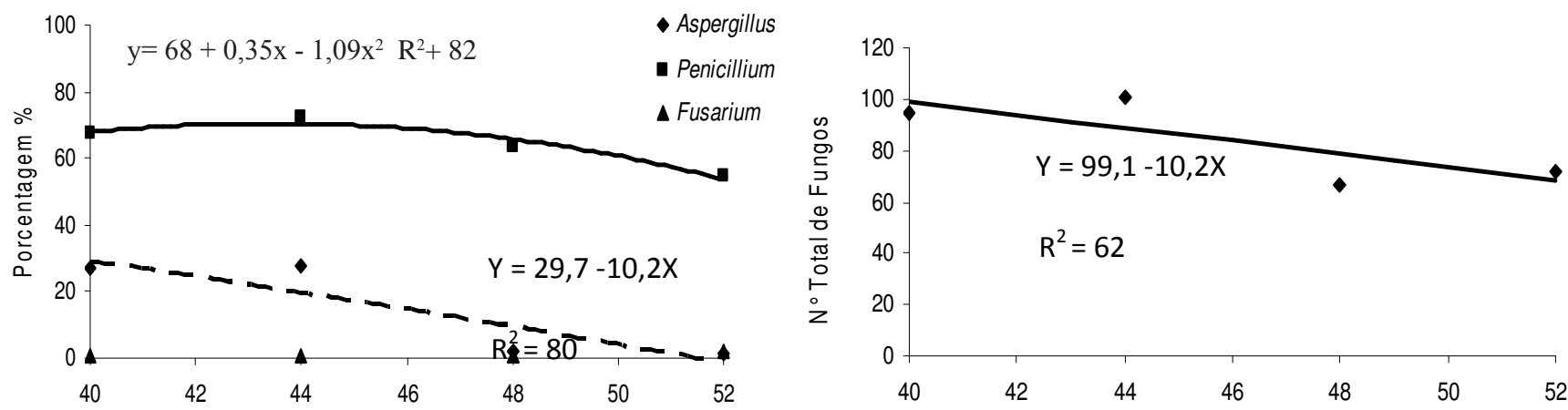

A

Dias após a antese

B

Dias após a antese

FIGURA 3. Análise de regressão para os resultados do testes de sanidade de sementes de milho da linhagem 3 . A Incidência dos fungos Aspergillus flavus, Penicillium sp. e Fusarium moniliforme; B - Número total de fungos em amostras de 100 sementes.

No que se refere à influência do fungo Fusarium na qualidade fisiológica de sementes, segundo estudos conduzidos por Whindam e King (1983) esse fungo caracteriza-se por apresentar infecção latente sem comprometimento da germinação ou emergência necessitando de condições de estresse para que o fungo se inicie a infecção. Em trabalho conduzido por Tanaka (2001) constatou-se a sobrevivência de $F$. moniliforme em sementes armazenadas durante período de 12 meses. Durante a germinação e emergência, Tanaka e Balmer (1980), evidenciaram o efeito de temperaturas baixas como fator predisponente à podridão de sementes e morte de plântulas. Nesse sentido, o tratamento de sementes com fungicidas, tecnologia que já vem sendo adotada de maneira efetiva em sementes de híbridos comerciais de milho, assume papel de fundamental importância. Trabalho conduzido por Moraes et al. (2003), avaliando o controle químico de F. moniliforme em sementes de milho, observaram que os tratamentos mais eficientes foram captan + tiabendazole e fludioxonil + metalaxil $(97,2 \mathrm{~g}+147,86 \mathrm{~g} / \mathrm{l})$, proporcionando controle acima de 90\% para a variável severidade.

Com relação às linhagens 2 e 3 , os fungos predominantes foram Aspergillus flavus e Penicillium sp., ao passo que o fungo Fusarium moniliforme apresentou incidência inferior a 5\%, não apresentando relações 
significativas (Figuras 2 e 3). Para os fungos Aspergillus flavus, Penicillium sp. e para a quantidade total de fungos, o comportamento foi semelhante ao observado na linhagem 1, com maior incidência aos 40 dias após a floração em relação as épocas mais tardias (Figuras 2 e 3), com exceção do fungo Penicillium sp. na linhagem 2, onde esse mesmo comportamento não pôde ser confirmado.

\section{CONCLUSÕES}

A incidência de microorganismos em sementes de milho durante o processo de maturação diminui à medida que se aproxima do ponto de maturidade fisiológica.

A presença de microorganismos até o ponto de maturidade fisiológica não afeta a qualidade fisiológica das sementes.

\section{REFERÊNCIAS}

AFUAKWA, J.J.; CROOKSTON, R.K. Using the kernel milk line to visually monitor grain maturity in maize. Crop Science, v.24, n.4, p.687- 691, 1984.

BORBA, C.B.; ANDRADE, R.V. de; AZEVEDO, J.T.; OLIVEIRA, A.C. de. Maturidade fisiológica de sementes do híbrido simples fêmea do milho BR201 (Zea mays L.). Revista Brasileira de Sementes, v.16, n.1, p.63-67, 1994.

BRASIL. Ministério da Agricultura e Reforma Agrária. Secretaria Nacional de Defesa Agropecuária. Departamento Nacional de Produção Vegetal. Coordenação de Laboratório Vegetal. Regras para Análise de Sementes. Brasília, DF, 1992. 365p.

CICERO, C.M.; SILVA, W.R. Danos mecânicos associados a patógenos e desempenho de sementes de milho. Bragantia, v.62, n.2, p.305-314, 2003.

FAHL, J.I.; CARELLI, M.L.C.; MONIZ, E.A.L.; OLIVEIRA, A.L.F. Avaliação da maturação de grãos de milho através da linha do leite para aplicação de dessecantes químicos. Bragantia, v.53, n.2, p.209-218, 1994.

FARIA, M.A.V.R.; VON PINHO, R.G.; VON PINHO, E.V.R.; GUIMARÃES, R.M.; FREITAS, F.E.O. Qualidade fisiológica de sementes de milho colhidas em diferentes estádios de "linha de leite". Revista Brasileira de Milho e Sorgo, v.1, n.1, p.93-104, 2002.

FEESEL, S.A.; MENDONÇA, E.A.; CARVALHO, R.V. Maturação fisiológica em sementes de milho. Revista Brasileira de Sementes, v.23, n.1, p.191-197, 2001.

HUNTER, J.L.; TEKRONY, D.M.; MILES, D.F.; EGLI,
D.B. Corn seed maturity indicators and their relationship to uptake of carbon-14 assimilate. Crop Science, v.31, n.5, p.1309-1313, 1991.

LUCCA FILHO, O.A. Diagnóstico da patologia de sementes de milho no Estado do Rio Grande do Sul. In: SIMPÓSIO BRASILEIRO DE PATOLOGIA DE SEMENTES, 1., 1984, Piracicaba, Situação e perspectivas da patologia de sementes no Brasil. Anais... Piracicaba: CENA/USP/ CNEN, Brasília, DF: ABRATES, 1984. p.102-104.

LUCCA FILHO, O.A. Testes de sanidade de sementes de milho. In: SOAVE, J.; WETZEL, M.M.V. da S. Patologia de sementes. Campinas: Fundação Cargill/ ABRATESCOPASEM, 1987, p.430-440.

MACHADO, A.A.; CONCEIÇÃO, A.R. Sistema de análise estatística para Windows. WinStat. Versão 2.0. UFPel, 2003.

MARTINS-FILHO, S.; LOPES, J.C.; RANGEL, O.J.P.; TAGLIAFERRE, C. Avaliação da qualidade fisiológica de sementes de soja armazenadas em condições de ambiente natural em alegre-es. Revista Brasileira de Sementes, v.23, n.2, p.201-208, 2001.

MORAES, M.H.D.; MENTEN, J.O.M.; GRAVENA, J.C.; ALVES, C.A. Controle químico de Fusarium moniliforme em sementes de milho: metodologia de avaliação e efeitos sobre a qualidade fisiológica. Fitopatologia Brasileira, v.28, n.6, p.626-632, 2003.

SHURTLEFF, M.C. A compendium of corn diseases. 2.ed. St. Paul: APS/University of Illinois, 1986. 105p.

TANAKA, M.A.S. Sobrevivência de Fusarium moniliforme em sementes de milho mantidas em duas condições de armazenamento. Fitopatologia brasileira, v.26, n.1, p.6064, 2001.

TANAKA, M.A.S.; BALMER, E. Efeito da temperatura e dos microrganismos associados do tombamento na germinação de sementes de milho (Zea mays L.). Fitopatologia Brasileira, v.5, p.87-93, 1980.

TANAKA, M.A.S.; CORRÊA, M.U. Influência de Aspergillus e Penicillium no armazenamento de sementes de feijão (Phaseolus vulgaris L.) Fitopatologia Brasileira, v.6, n.3, p.451-456, 1981.

TEKRONY, D.M.; HUNTER, J.L. Effect of seed maturation and genotype on seed vigor in maize. Crop Science, v.35, n.3, p.857-862, 1995.

WINDHAM, M.T.; KING, S.B. Microflora of roots of maize at seedling and silking stages in Mississipi. Plant Disease, v.67, p.1366-1368, 1983. 